\title{
POR QUE CALAFRIOS?: INTERAÇÕES ENTRE IMAGEM, CORPO E DESEJO EM YVONNE RAINER
}

Mariana Patrício Fernandes

Imagem não é nada - você tem sede de quê?

\section{Primeira cena: Anúncio publicitário na televisão}

Um jogador de basquete, solitário, concentrado diante da cesta em um cenário escuro. Ele quica a bola algumas vezes antes de lançar-se a uma monumental "enterrada", saltando mais alto que o próprio Nijinski, ao som de um canto lírico que propicia o clima de desafio. De repente, quando a bola está sendo afundada com vigor para dentro da cesta, ouvimos um inesperado grito de "corta!" vindo de um diretor do comercial. As luzes se acendem, observamos a grua utilizada na filmagem da cena, assim como a equipe no set e o fio que segurava o jogador propiciando seu salto fenomenal. Uma típica voz de locutor de anúncio publicitário diz então: "Imagem não é nada, sede é tudo! Não acredite em tudo o que vê. Obedeça a sua sede: Sprite!"

\section{Segunda cena: Uma visão aérea de uma paisagem devastada, ir- reconhecível. Em off, a voz de jovem lê seu diário:}

Ontem eu fui a uma assembleia no 306. Uma menina cantava "Come, come, I love you truly" de Chocolate Soldier. Enquanto ela cantava, eu comecei a sentir as sensações mais estranhas. Calafrios colapsavam todo o meu corpo. Correntes de suor frio me percorriam. Achei que estava doente, mas quando ela parou os calafrios me deixaram. Frequentemente essas sensações vêm a mim quando eu escuto ou leio a respeito de alguma espetacular experiência humana de bravura ou perseverança, ou alguma história de grande apelo emocional. Algumas vezes essas histórias são absoluta ou excessivamente melodramáticas, como a que Louise Utis contou na aula de inglês sobre um G.I, que se corresponde com uma menina com a qual ele pretende se casar assim que voltar da guerra. Depois de uma batalha seu rosto fica cheio de cicatrizes além de ficar aleijado. No dia antes de seu navio ancorar nos EUA, a me- 
nina é atropelada por um carro. Ela sofre de uma sequela cerebral séria que resulta em cegueira. De qualquer forma, durante as últimas frases eu senti arrepios. Eu luto muito contra eles porque eu basicamente rejeito essas histórias pela sua natureza artificial e irrealista. A intensidade dramática é sempre tão afastada da minha própria vida que me deixa com um sentimento vazio... Em nome de Deus, então, o que esses malditos calafrios significam?

As duas cenas acima descritas, a primeira de um comercial da marca de refrigerante Sprite veiculada na televisão em 2006 e a segunda uma passagem do filme de Yvonne Rainer, Journeys from Berlin de 1975, são bastante significativas para ajudar a pensar o questionamento principal deste artigo: de que forma, em um mundo saturado de estímulos visuais e sensoriais que parecem a todo momento direcionar o desejo, podemos reconhecer a autenticidade de suas sensações? Para procurar alguns encaminhamentos que nos ajudem nessa investigação, analisamos algumas passagens da trajetória da cineasta e coreógrafa Yvonne Rainer nas quais encena e pensa, de forma singular, as tensōes existentes entre corpo e subjetividade.

A fórmula do anúncio publicitário que compõe a primeira cena de nosso texto parece ser uma perfeita exemplificação da expressão popular que diz que o feitiço se volta contra o feiticeiro, ou ainda da afirmação de que o capitalismo contemporâneo sobrevive por ser capaz de se apropriar de suas próprias críticas e crises. Como não pensar nos postulados dos críticos da cultura de massa na pós-modernidade como Jameson, Baudrillard e Debord ${ }^{1}$ ao ouvir a voz sedutora do locutor ordenando que não acreditemos em tudo o que se vê, obedecendo a nossa própria sede... sprite. $\mathrm{Na}$ forma como o texto é dito e projetado na tela da televisão, sede e sprite aparecem como sinônimos, numa forma um tanto perversa, se acreditarmos que o espectador não tem nenhuma ferramenta para desconfiar daquilo que vê (como manda, aliás, o anúncio).

\footnotetext{
${ }^{1}$ Em Além do visivel $-O$ olhar da literatura Karl Erik Schøllhammer ressalta a semelhança entre o que Jean Baudrillard intitulava "era da simulação da terceira ordem" e o reconhecimento por Frederic Jameson de uma "terceira Revolução tecnológica". Em ambas as visôes acredita-se que: "o regime representativo totalizado provocaria a queda de todo referente exterior aos meios de comunicação, usurpando o lugar do mundo real em relação à verdade. Até mesmo os sonhos individuais e os desejos íntimos são comercializados como necessidades que o mercado está sempre pronto para satisfazer."*
}

* (SCHØLLHAMMER, Karl Erik. Além do visível: Oolhar da literatura. Rio de Janeiro: 7letras, 2007: 41.) 
- (DEBORD, Guy. A sociedade do espetáculo. Rio de Janeiro: Contraponto, 1997: 13.)
- (PELBART, Peter. Vida nua, Vida besta, Uma vida. In: Revista Trópico: dossiê, 25/10/2006. Extraído do site: http://pphp.uol.com.br/ tropico/html/indice/6,1.shl)
O alerta do locutor é semelhante ao que lançava Guy Debord em 1976 na primeira edição de seu célebre livro $A$ sociedade do espetáculo:

A especialização das imagens do mundo se realiza no mundo da imagem autonomizada, no qual o mentiroso mentiu para si mesmo. O espetáculo em geral, como inversão concreta da vida, é o movimento autônomo do não vivo"*

Mas o que significa essa não vida de que fala Debord, ou a "vida-besta" para usar a expressão cunhada por Peter Pal Pélbart? Uma das características principais dessa forma de existência bastante popularizada no mundo contemporâneo parece ser a incapacidade de reconhecermos a autenticidade do nosso próprio desejo, confundindo a nossa própria sede com o logotipo da marca de um refrigerante. Segundo Pélbart:

[...] na pós-política espetacularizada, e com o respectivo sequestro da vitalidade social, estamos todos reduzidos ao sobrevivencialismo biológico, à mercê da gestão biopolítica, cultuando formas de vida de baixa intensidade, submetidos à morna hipnose consumista, mesmo quando a anestesia sensorial é travestida de hiperexcitação. É a existência de ciberzumbis, pastando mansamente entre serviços e mercadorias, e como dizia Gilles Châtelet, viver e pensar como porcos. Vida besta é esse rebaixamento global da existência, essa depreciação da vida, sua redução à vida nua, à sobrevida, estágio último do niilismo contemporâneo."

Essa existência normatizada e repetitiva parece indissociável da manipulação de imagens pelos meios de comunicação, como demonstrado de forma irônica e metalinguística no anúncio do Sprite. As imagens do corpo, que não param de proliferar nas telas de TV e bancas de jornal, promovem e disseminam o desejo por uma forma perfeita, afetando de forma irremediável nossa relação com a corporeidade. Parece impossível atualmente pensar em corpo de forma desvinculada de sua relação com a imagem - como se toda sede necessitasse de algum estímulo visual para ser provocada.

A busca pela forma perfeita, como escreve Pélbart, não está desvinculada da obsessão de despertar o desejo do outro por nós, como se esta fosse uma maneira de provar para nós mesmos que existimos. O outro funcionaria aqui como um espelho que garante a formação da identidade. E não se trata de um problema individual a ser resolvido no divã do psicanalista. Os inúmeros guetos e minorias que proliferam no mundo contemporâneo conhecem de 
perto os estragos que podem causar à própria vida o fato de permanecer invisível diante do resto da sociedade. Construir uma imagem positiva parece indispensável para estar inserido no mundo capitalista de nossos dias, como lembra Evelyne Grossman:

Parce qu'elle se participe de la construction du lien social, du vivre ensemble (se reconnaître dans les mêmes formes, les mêmes signes d'appartenance), l'image est grégaire par vocation. Elle privilégie les effets de groupe, de ressemblance (être comme l'autre), de conformisme.

Nessa ausência de separação entre um desejo próprio e um produzido externamente, o corpo reage como um estranho produzindo sensações desconhecidas, sede fora de hora, dificuldade de dizer não a essa proliferação de estímulos visuais que muitas vezes vão de encontro ao ideal de harmonia e moderação promovido pela imagem perfeita, necessitando para o seu controle de um extenso aparato de medicamentos e tratamentos estéticos que mantenham intacto o seu desejo de perfeição.

No depoimento expresso de modo juvenil e inocente (que reconhecemos através da voz da menina que não vemos) extraído do filme de Yvonne Rainer, Journeys from Berlin, de 1971, reconhecemos esse angustiante estranhamento da personagem diante das próprias sensações. Por que os arrepios? Qual será o canal que leva da audição das músicas e histórias melodramáticas e cafonas ao estremecimento do corpo, se sou uma moça engajada (o incidente se deu na ida a uma assembleia) que procuro afastar da minha vida esse tipo de emotividade, a hiperexcitação travestida de que fala Pelbart. Algo se passa com força para além do plano ideológico, ideal, que atinge diretamente o corpo sem pedir concessão à consciência. Como reagir? Como resistir? Será mesmo preciso?

\section{A mente é um músculo - a renúncia à espetacularidade e a busca pela objeticidade do corpo em Trio $A$}

O questionamento de Yvonne Rainer a respeito da relação entre corpo e imagem começou cedo em sua carreira. Participante do movimento da Judson Church, que revolucionou, nos anos 1960 , quase todos os pressupostos da dança ocidental (desde a utilização de espaços cênicos não convencionais até o primado do virtuosismo no ofício do bailarino), Rainer esteve particularmente empenhada em problematizar o caráter de espetacularidade em suas co-
* (GROSSMAN, Evelyne. La Défiguration: Artaud, Michaux, Beckett. Paris, Les Editions de Minuit, 2004: 8-9.) 
- Peço que os movimentos sejam executados claramente, sem que se inclua nenhuma expressividade. O que vemos deve ser realmente o movimento de um ou outro bailarino, e não algo que ele ou ela acrescentou e que dificulta a visão. Quero ver a forma que toma um movimento em um bailarino e nada mais. Devo vê-lo de forma clara e diferente em corpos diferentes. (Entrevista extraída de FEBVRE, Michele. Danse contemporaine et théâtralité. Paris: Éditions Chiron, 1995: 20.)

- A dança é difícil de se ver. Ou ela deve ser feita com menos extravagância, ou essa dificuldade intrínseca deve ser enfatizada ao ponto de ela se tornar quase impossível de se ver. (RAINER; Yvonne, apud BANES. 1987: 45). reografias, realizando peças coreográficas marcantes pelo seu minimalismo e pela recusa à teatralidade, posturas que, acreditava, impediam que a dança se desviasse de seu principal elemento cênico: o corpo. The mind is a muscle (1968), título de um dos seus mais conhecidos espetáculos, que tinha a duração de praticamente uma noite inteira, expressa bem essa preocupação. Ao longo de sua trajetória, no entanto, Rainer começa a deixar cada vez mais em segundo plano as atividades coreográficas para dedicar-se ao cinema, onde não abandona por completo as estruturas narrativas, o recurso aos personagens e outros componentes negados no início de sua carreira como dançarina e coreógrafa, por razões que vamos agora tentar analisar.

Alunos de Merce Cunningham, os integrantes da Judson trouxeram consigo os movimentos antiexpressivos por ele empregados, assim como as composições que fugiam da estrutura narrativa por meio da utilização do método do acaso, das criações de Cunningham com John Cage. Para esses jovens artistas, ${ }^{2}$ no entanto, as rupturas com o caráter expressionista da dança moderna, executadas pelo mestre, não chegavam à radicalidade por eles pretendida, pois primavam por uma abordagem do movimento ainda muito centrada na figura e na forma. Se, por um lado, Cunningham pensava em uma estética cênica livre de intenção, na qual procurava diminuir o caráter significante da figura humana e de sua motricidade, ele o fazia privilegiando a clareza da imagem produzida em cena. Para ele, o corpo deveria dar uma resposta que fosse claramente visível, como explica em uma entrevista:

Je demande que les mouvements soient exécutés clairement, sans y faire entrer aucune expressivité. Ce doit être vraiment le mouvement qu'on voit en train de se faire chez tel ou tel danseur et pas quelque chose qu'il ou elle ajoute et qui rend la vision plus difficile. Je veux voir la forme que prend tel mouvement sur tel danseur et rien d'autre. Je dois le voir clair et différent sur des corps différents.

Pensando aqui no trabalho coreográfico de Yvonne Rainer, podemos apontar justamente nessa clareza de visibilidade o maior ponto de contradição com seu antigo professor. Para Rainer, a dança deveria, inversamente, ser difícil de ver:

Dance is hard to see. It must either be made less fancy, or the fact of that intrinsic difficulty must be emphasized to the point that it becomes almost impossible to see.

\footnotetext{
${ }^{2}$ Além de Rainer, participavam da Judson Dance artistas como Steve Paxton, Trisha Brown, entre outros.
} 
Essa dificuldade não deveria ser causada pelo excesso de subjetivismo ou de artifícios que tirassem do corpo e do movimento o foco principal da criação coreográfica, mas, inversamente, por um esforço em colocar em questão justamente o lugar que ocupa o bailarino na cena, combatendo, ao mesmo tempo, a dimensão espetacular da dança. NO Manifest é o documento em que Rainer anuncia o que pretende manter longe da cena e do corpo em suas criaçóes:

Não ao espetáculo, não ao virtuosismo, não às transformações e à magia e ao uso de truques, não ao "glamour" e à transcendência da imagem da star, não ao heroísmo, não ao anti-heroísmo, não às imaginárias de pechisbeque, não ao comprometimento do bailarino ou do espectador, não ao estilo, não às maneiras afetadas, não à sedução do espectador graças aos estratagemas do bailarino, não à excentricidade, não ao fato de alguém se mover ou se fazer mover. ${ }^{*}$

Levando adiante as premissas expostas no manifesto, Rainer empenha-se na criação de uma coreografia que encarnasse essas novas configuraçōes do que se entende por dança. Trio A, criada em 1966, é emblemática desse novo modo de coreografar, pondo a nu, segundo Gil, "as condiçôes de possibilidade de qualquer obra dançada". Trata-se agora de ver, entretanto, como a coreógrafa pôde, a despeito da radicalidade de seu gesto, dançar essa impossibilidade, criando, para utilizar a expressão de Sally Banes, uma "estética da recusa."*

$\mathrm{Na}$ cena, vemos uma série de frases de movimentos que se conectam umas nas outras provocando a sensação de um fluxo contínuo, sem que o espectador possa perceber onde termina uma sequência e se inicia outra. Os movimentos que compóem esse fluxo parecem se apresentar em um perpétuo desvanecimento, pois, uma vez engendrados, logo desaparecem. A mesma quantidade de energia é empregada na execução das séries sem que haja momentos de climas, ou qualquer descontinuidade entre as sequências. Não descobrimos o que faz com que o corpo se mova, uma vez que não se trata da intenção da bailarina ou da finalidade de seus gestos. Movimentos aparentemente cotidianos e simples ganham uma carga de estranheza justamente pela impossibilidade de reconhecermos neles alguma motivação familiar. Não há identificação possível do espectador com a cena, o que torna bem-sucedido o desejo de Rainer de que a dança seja difícil de ver.

O corpo da bailarina em cena, enquanto executa a coreografia, não apresenta nenhum esboço de teatralidade ou dramatização. Não é um personagem que dança, e tampouco é a subjetivi-
(Apud GIL, José. Movimento Total: O corpo e a dança. Lisboa: Iluminuras, 2005: 151.)

" (GIL, José. Movimento Total: O corpo e a dança. Lisboa: Iluminuras, 2005: 167.)

(BANES, Sally. Terpsichore in sneakers: post-modern dance. Middletown: Wesleyan University Press, 1987.) 
- Se a minha raiva com o empobrecimento das ideias, o narcisismo, e o exibicionismo sexual disfarçado na maioria das danças pode ser considerada moralismo puritano, é também verdade que eu amo o corpo - seu peso efetivo, massa e sua fisicalidade natural. É a minha principal preocupação mostrar as pessoas envolvidas em vários tipos de atividades - sozinhas, com outros, com objetos - e pesar a qualidade do corpo humano diante daquela dos objetos e longe da superestilização do bailarino. (RAINER, Yvonne, apud WOOD, Catherine. Yvonne Rainer: The mind is a muscle. Massachussets: MIT Press, 2007:34.) dade da própria bailarina quem comanda a movimentação. Essa ausência de dramaticidade ou subjetividade se constrói em vários níveis. Em primeiro lugar, o olhar do bailarino jamais se oferece ao espectador. $\mathrm{O}$ olhar aqui é negado tanto por sua dimensão de "janela da alma", uma passagem que deixaria entrever a interioridade de um sujeito, quanto como elemento preponderante do estabelecimento de uma relação com o outro que reforça a premissa existente no manifesto: "Não à sedução do espectador graças aos estratagemas do bailarino."

Nesse movimento de afastamento da subjetividade, do erotismo (através da sedução do espectador) e de teatralidade (os elementos cênicos quase não são utilizados), a relação do dançarino com seu corpo busca se aproximar de uma relação de objeticidade. Como ressalta Banes, as composições coreográficas que engendravam uma nova relação com os objetos em cena já vinham sendo experimentadas pelos integrantes do Judson. Interessava-lhes sua especificidade material, seu peso-forma-volume com os quais os bailarinos deveriam interagir. O uso dos objetos (arrastar móveis pesados no palco, por exemplo) alterava o tipo de movimento a ser utilizado em cena, removendo o drama da performance. A partir desse trabalho, pode-se pensar o próprio corpo "como um objeto, que deveria então ser examinado friamente sem motivações psicológicas sociais ou mesmo formais". " Rainer complexifica o sentido da adoção dessa postura frente ao corpo em um texto pertencente ao programa de The mind is a muscle:

If my rage at the impoverishment of ideas, narcissism, and disguised sexual exhibitionism of most dancing can be considered puritan moralizing, it is also true that I love the body - its actual weight, mass and unenhanced physicality. It is my overall concern to reveal people as they are engaged in various kinds of activities - alone, with each other, with objects - and to weigh the quality of the human body toward that of objects and away of the superstylization of the dancer.

Chegamos aqui a um ponto que nos parece interessante discutir. No trecho citado, vemos uma relação estabelecida pela diretora entre a atenção conferida aos elementos objetivos do corpo humano com o desejo de combater tanto o narcisismo quanto o que ela chama de "exibicionismo sexual" do performer. No entanto, o que aponta para um caráter de engajamento político na criação da diretora é logo negado por ela, de forma paradoxal, é importante ressaltar, em outra passagem do mesmo texto: 
The condition for the making of my stuff lies in the continuation of my interest and energy. Just as ideological issues have no bearing on the nature of the work, neither does the tenor of current political and social conditions have any bearing on its execution. The world disintegrates around me. My connection to the world in crisis remains tenuous and remote. I can foresee a time when this remoteness must necessarily end, though I cannot foresee exactly when or how the relationships will change, or what circunstances will incite me to a different kind of action [...] This statement is not an apology. It is a reflection of a state of mind that reacts with horror and disbelief upon seeing a Vietnamese shot dead on TV - not at the sight of death, however, but at the fact that the TV can be shut afterwards as after a bad western. My body remains the enduring reality.

A relação paradoxal com a presença de questionamentos políticos em The mind is a muscle também se apresenta na própria advertência presente logo abaixo do título da Declaração exposta no programa: "It is not necessary to read this prior to observation."3 Fica claro aí o posicionamento da coreógrafa, nesse momento de sua trajetória, diante do uso da linguagem e de suas possíveis significações ideológicas e políticas. Ao afirmar que o texto não precisa ser lido e que questōes ideológicas não fazem parte da cena é como se Rainer estivesse utilizando a escrita e o debate político para conseguir paradoxalmente retirar a sua presença do corpo. A mesma postura de busca da neutralidade da bailarina em cena, que não nega a carga significante do corpo, mas a combate explicitamente, é a da diretora em relação ao espetáculo.

Ao nos deparamos com a neutralização da expressividade do bailarino e com a ausência de movimentos à primeira vista ordinários, seguindo um mesmo fluxo de energia, o que experimentamos diante de Trio $A$ é a sensação de estarmos assistindo a uma série absolutamente singular de movimentos inéditos, como se os gestos semelhantes aos do cotidiano estivessem sendo realizados pela primeira vez em cena. É como se, de fato, a coreógrafa tivesse conseguido libertar o corpo da carga pesada de significações que o impediam de ser algo além de um "meio de expressão". Esse corpo livre de significações exteriores a ele se apresentaria em Trio A como a realidade que resiste ao "mundo em crise" à sua volta, em sua "fisicalidade", como escreve Rainer no programa de The mind is a muscle. Não é por acaso que essa peça coreográfica é até hoje ensinada a alunos de dança como exercício prático e reencenada em
*A condição da criação das minhas coisas reside na continuação do meu interesse e da minha energia. Assim como questões ideológicas não têm nenhuma presença na natureza do trabalho, tampouco o tem o curso geral das condições políticas e sociais em sua execução. Minha conexão com o mundo em crise permanece tênue e remota. Eu posso prever um tempo em que esse alheamento deve necessariamente acabar, apesar de não conseguir prever exatamente quando ou como a relação irá mudar, ou quais circunstâncias me incitarão a um outro tipo de ação [...] Essa declaração não é um pedido de desculpas. É o reflexo de um estado de espírito que reage com horror e descrença ao ver um vietnamita sendo morto na TV - não pela visão da morte, mas pelo fato de que a televisão pode ser desligada em seguida, como depois de um filme de faroeste de maugosto. Meu corpo permanece sendo a realidade que resiste. (Ibidem:34.)

\footnotetext{
3 "Não é necessário ler esse texto como prévia do espetáculo."
} 
Com Trio A, de Rainer, o ciclo se quebra, por fim. O debate torna-se irrelevante. Propõe-se a possibilidade de que a dança não seja nem perfeição, nem técnica, nem expressão, mas alguma coisa bem diferente - a apresentação dos objetos como são. Não é simplesmente um novo estilo de dança, mas um novo sentido e uma nova função, uma nova definição de dança que aparece. (BANES, Sally. Terpsichore in sneakers: post-modern dance. op. cit.: 49.)
•(GIL, José. Movimento Total: O corpo e a dança. Lisboa: Iluminuras, 2005: 152.) festivais pelo mundo, já tendo sido dançada inúmeras vezes por bailarinos profissionais e mesmo por não bailarinos. Para Sally Banes essa obra quebra o ciclo vicioso instaurado pelo conflito entre técnica e expressividade, que orientou a dança no Ocidente desde sua autonomização:

With Rainer's Trio $A$ the cycle is at last broken. The debate is made irrelevant. The possibility is proposed that dance is neither perfection, nor technique nor of expression, but quite something else - the presentation of objects in themselves. It is not simply a new style of dance, but a new meaning and function, a new definition of dance that has appeared.

Então, uma vez rompido esse ciclo vicioso e aberta uma nova gama de possibilidades do que até então se entendia por dança, como entender as motivaçôes que desviaram cada vez mais Rainer das criações coreográficas para engajar-se cada vez mais na direção de filmes para o cinema?

Analisando o Manifesto, assim como a execução de Trio A, José Gil compara esse corpo radical de recusas, que põe em xeque o próprio estatuto da dança (sobretudo a última "enigmática" sentença que nega o próprio movimento), com o gesto de Duchamp e seus ready-mades no início do século XX. Para Gil, após negar tudo aquilo que seria exterior à dança, Rainer defronta-se de fato com o limite da existência da própria arte:

Mas o que é um movimento em estado nu? Tal movimento não existe, há sempre uma motivação que faz mexer o corpo, há sempre uma razão exterior ao movimento que faz com que este último comece: retirar esse resíduo último estranho ao movimento éalcançar enfim a pureza essencial do movimento e é também anulá-lo totalmente. Duas afirmaçōes que Yvonne Rainer foi obrigada a sustentar ao mesmo tempo.

Será essa a resposta? Ao romper com toda a referencialidade na dança, com a "razão exterior" ao movimento de que fala José Gil, Trio $A$ terá também impossibilitado a sua própria criadora de, a longo prazo, continuar a coreografar?

\section{A quase "seminarrativa" e o retorno do impulso desejante}

Em uma entrevista a Veronique Fabbri em 2003, ${ }^{4}$ Yvonne Rainer explica de forma breve que sua passagem da dança ao cinema se

\footnotetext{
${ }^{4}$ Por ocasião do colóquio Le public au singulier pluriel em Paris, organizado conjuntamente pelo Centre National de la Danse e pelo Collège International de Philosophie. Reproduzida na Revista Rue Descartes. n.44. Paris: PUF, 2004.
} 
deveu ao seu desejo de abordar questões políticas e sociais, de um modo que já não conseguia ser capaz de fazer como dançarina:

Je voulais moi aussi me pencher sur des questions sociales de façon plus précise; mais étant donné ce que je faisais de la danse et ce que j'avais envie de faire, il me semblait que ce n'était pas avec la danse que je pouvais aborder ce type de problématique; c'est d'ailleurs une des principales raisons pour lesquelles je me suis tournée au cinéma.

Parecia-lhe, de um lado, que seu intuito de neutralidade do corpo na dança havia se tornado um modo um tanto "ingênuo" (para usar suas palavras) de problematizar o narcisismo na cena, assim como a questão do olhar entre plateia e espectador. Rainer, na mesma entrevista, comenta o traço naïf dessas tentativas ao relembrar a coreografia em que pinta o rosto de negro, com o intuito de neutralizar a sua expressão em um momento em que os Estados Unidos eram palco de uma intensa luta pelos direitos civis dos negros:

Avec le recul cela peut sembler un peu naiff, parce que c'était à la grande époque du combat pour les droits civiques aux États-Unis, mais mon travail n'avait aucun rapport avec cela. C'était simplement une autre manière pour moi d'effacer les traits de mon visage, de façon à contraindre le public à voir le mouvement dans sa qualité objectale, et non comme l'expression de la personnalité du danseur telle qu'elle se manifeste dans le visage.

Por outro lado, Rainer parece pôr em questão a própria possibilidade de uma neutralidade em cena, citando Freud na entrevista: "Todos os poros da nossa pele nos traem.”* Essa traição é o tema da fala em off da menina que lê seu diário em Journeys from Berlin, citada no início deste artigo, e que soa quase como um depoimento autobiográfico quando o relacionamos com a trajetória de Rainer.

"A intensidade dramática é sempre tão afastada da minha própria vida que me deixa com um sentimento vazio... Em nome de Deus então, o que esses malditos calafrios significam", pergunta a jovem, espantada com as sensações experimentadas ao ouvir histórias ou cançôes com intensa carga melodramática. Em Journeys from Berlin, a separação do mundo em crise que o bailarino espanta da cena com seu corpo objetal não expressivo parece implodida. $\mathrm{O}$ filme apresenta uma série de fragmentos de imagens, vozes e textos justapostos que discutem simultaneamente as ações políticas do grupo de esquerda alemão Baader-Meinhof e das anarquistas russas do século XIX, as confissões de uma mulher diante do psicanalista e a intimidade de um casal em sua cozinha, em uma estrutura que a diretora chama de "quase seminarrativa".
"Eu também queria me debruçar sobre as questões sociais de forma mais precisa. Mas levando em conta o que eu fazia na dança, e aquilo que eu tinha vontade de fazer, me parecia que não seria através da dança que poderia abordar esse tipo de problemática. Essa é, inclusive, uma das principais razões da minha virada em direção ao cinema. (RAINER, Yvonne; Catherine Delaruelle. "Danse publique et communauté: Trio A et autres pièces ou films d'Yvonne Rainer". Rue Descartes 2. n. 44. Paris: PUF, 2004: 91.)

"Distanciadamente pode parecer um pouco naïf, porque era a época dos grande combates pelos direitos civis nos Estados Unidos, mas meu trabalho não tinha nenhuma relação com isso. Para mim, simplesmente era um outro modo de apagar os traços do meu rosto de modo a obrigar o público a ver meus movimentos em sua qualidade objetal e não como expressão da personalidade do dançarino, tal como ela se manifesta no rosto. (Ibidem: 89.)

(Ibidem: 88). 
A questão da visibilidade e a problematização da posição do olhar do espectador diante das cenas continuam presentes, mas são abordadas sob um novo ângulo. A dificuldade da visão que Rainer pretendia despertar na dança se intensifica com a justaposição aleatória entre a imagem, o texto escrito e as vozes em off, promovendo ainda uma dificuldade de compreensão da linguagem e destituindo a dicotomia entre a opacidade do corpo e a clareza da linguagem que parecia orientá-la em suas coreografias. Ao mesmo tempo que uma tela escura projeta um texto histórico relatando as ações do Baader-Meinhof, ouve-se em off a discussão do casal na cozinha pensando no que vai comer para o jantar enquanto debate a legitimidade do uso da violência em suas açôes políticas. A jovem lê seu diário ao mesmo tempo em que aparecem em cena imagens aéreas de uma terra devastada.

Bastante influenciada pela crítica feminista do cinema, Rainer procura impedir que o espectador se coloque na posição confortável do olhar soberano em relação às imagens, que ela relaciona com o olhar masculino diante do objeto de desejo (em determinado momento, após uma sequência de cenas em que se apresentam imagens aéreas de paisagens desérticas ou devastadas, ouvimos o barulho do helicóptero de onde essas imagens estariam sendo filmadas, ao mesmo tempo em que vemos um dos cabos da sua parte de baixo projetado como um verdadeiro falo).

No entanto, se em Trio $A$ ela colocava essa crítica a partir de uma negação completa da narratividade e da dramaticidade, em Journeys from Berlin a estrutura "quase seminarrativa" não rejeita completamente as intensidades melodramáticas, os momentos de sedução, seja pela suavidade das vozes em off, seja pela beleza de algumas imagens. Esses fragmentos, porém, não são capazes de restituir um direcionamento linear ao olhar desejante do espectador, pelo contrário, são como trilhas que levam a lugar nenhum, aparições efêmeras que impedem a construção de um sentido.

Até o momento, tudo indica que Rainer tenha conseguido restituir no cinema o impulso desejante que leva à criaçáo, e que ela recusou nas composições coreográficas ao negar o próprio impulso externo que leva ao movimento, como apontou José Gil. Seria então preciso concluir que não é possível dançar sem permanecer na dicotomia entre expressão e objetividade? Ou ainda, a dança jamais poderia aludir à política sem apresentar um corpo unitário (incapaz da fragmentação atingida por Rainer no cinema), no qual a expres- 
são de uma subjetividade narcisista ou da busca por belas formas é inevitável? O corpo não conseguiria sair do seu lugar ou de objeto desligado do mundo que turbilhona à sua volta ou de objeto passivamente submisso a uma enxurrada de significações, sem reconhecer a própria sede e estremecendo diante de qualquer manifestação piegas de emotividade, sempre passível de manipulação?

\section{Conclusão: A dança exaustiva e o corpo que não aguenta mais}

Assistimos atualmente em algumas apresentações de dança contemporânea a uma retração dos corpos em relação ao movimento. Em um marcante festival de Still acts (paragens) em 1992 em Paris, Skite, alguns coreógrafos europeus expuseram a sua necessidade de optar por esse gesto de recusa do movimento como uma relação com os fenômenos políticos recentes - a Guerra da Bósnia, por exemplo -, que os impediam de expandi-lo.

O crítico André Lepecki relembra esse evento como um acontecimento que desvelou a impossibilidade de manter o alinhamento entre dança e movimento que havia orientado o paradigma moderno dessa arte.*

Combatendo a vertente crítica que reconhece nesses trabalhos, marcados pelas intermitências, as pausas e a impossibilidade de criação de fluxos contínuos, uma declaração do "fim da dança", o autor sugere que é preciso repensar o que durante a modernidade pareceu tão natural que não valia a pena discutir: o movimento. Dessa forma, é contundente ao criticar o que denomina de "fantasia moderna de que toda a subjetividade ganharia seu impulso em direção ao movimento sem questionar qual a fonte de energia que o impulsiona"* Os corpos retraídos das recentes manifestações performáticas representariam um novo modo de pensá-lo em relação às pressões históricas e subjetivas que o cercam, levando adiante os questionamentos colocados por Yvonne Rainer desde as suas primeiras coreografias.

Esses dançarinos que pouco se movem, ou se movem com dificuldade (pensamos aqui em Xavier Le Roy deitado de costas para a plateia encostado a uma parede, em um fragmento intitulado "o morto", parte de seu espetáculo Royal, ou em Vera Mantero se equilibrando com dificuldade em altíssimos saltos que lembram pés de cabra em Uma misteriosa coisa disse E.E Cummings), são citados por David Lapoujade em um texto intitulado $O$ corpo que não aguenta mais. Nele o autor afirma que esse não aguentar mais do corpo é sua condição incontornável na contemporaneidade:
* (LEPECKI, André. Exhausting Dance: performance and the politics of movement. Nova York: Routledge, 2006: 16.)

"(lbidem: 15.) 
(LAPOUJADE, David. "O corpo que não aguenta mais". In: LINS, Daniel; GADELHA, Sylvio (orgs.) Nietzsche e Deleuze: que pode o corpo. Rio de Janeiro: Relume Dumará, 2002: 82.)

"(Ibidem: 84.)

(Ibidem: 82.)
Não se trata de um postulado nem de uma tese, mas de um fato. Basta considerar, por exemplo, o domínio da arte de hoje em dia, onde se multiplicam posturas elementares: sentado, esticado, inclinado, imobilizado, os dançarinos que escorregam, os corpos que caem ou se torcem, que se mutilam, que gritam, os corpos desacelerados, adormecidos. Somos como personagens de Beckett, para os quais já é difícil andar de bicicleta, depois difícil andar, depois, difícil simplesmente se arrastar, e depois ainda, permanecer sentado.

O que o corpo não aguenta mais são as formas de disciplina que o coagiram desde o exterior, na modernidade, em um processo de adestramento demonstrado por Nietzsche em A genealogia da moral e por Foucault em $A$ história da sexualidade, e tampouco as formas de controle que parecem contemporaneamente ter interiorizado na consciência o projeto normativo, transformando-o em assujeitamento. ${ }^{*}$ Já não haveria, atualmente, necessidade de instituições disciplinares, pois são os próprios sujeitos que se vigiam permanentemente em prol da conquista de uma conduta correta, um corpo adequado, uma imagem perfeita. Lapoujade propõe, diante dessa constatação, que se repense a concepção aristotélica de potência, na qual o corpo depende de um agente para ganhar forma. No corpo contemporâneo que não aguenta mais, "tudo se passa como se ele não pudesse mais agir, não pudesse responder ao ato da forma, como se o agente não tivesse mais controle sobre ele."*

Dançar essa condição é estabelecer uma relação entre dança e política que Yvonne Rainer negou por receio de que a intromissão de questões ideológicas na cena restabelecesse a hierarquia entre pensamento e corpo da qual pretendia se esquivar ao procurar ressaltar a "fisicalidade" do segundo para além de suas significações externas. Como afirma Lapoujade, dizer que o corpo não aguenta mais é também reconhecer que ainda não começamos a pensar. Se chegamos contemporaneamente a um ponto em que qualquer ação ou assertiva parece de antemão capturada pela rede de significados do biopoder, "se fingir de morto" como Xavier LeRoy constitui quem sabe a atitude mais potente nos dias que correm. Paramos por aqui. 


\section{Mariana Fernandes}

É doutoranda em Letras pela PUC-RIO, e pesquisa atualmente as relações entre subjetividade, política e erotismo na dança contemporânea sob orientação da prof Ana Paula Kiffer. É mestre em Literatura pela mesma instituição e graduada em História também pela PUC.

\section{Resumo}

Desde os anos 1960, no cenário de vanguarda nova-iorquina de Greenwich Village, Yvonne Rainer enveredou no cinema e na dança pela investigação das potencialidades intrínsecas do corpo, "sua fisicalidade", como chamava. As relações entre corpo, política e a subjetividade, tomaram formas diversas e paradoxais durante o percurso de Rainer. O presente artigo procura estabelecer um diálogo entre o trabalho da coreógrafa e alguns questionamentos contemporâneos sobre as relações entre corpo e imagem.

\section{Resumé}

Dès le début des années soixante, dans le contexte d'avant-garde new-yorkais du Greenwich Village, Yvonne Rainer fut impliquée dans la recherche des potentialités intrinsèques du corps, «sa physicalité», comme elle le disait. Les rapports entre le corps, la politique et la subjectivité ont pris des formes diverses et paradoxales le long du parcours de Rainer.

Cet article a pour but de mettre en dialogue le travail de la coréographe et certaines réflexions contemporaines sur les rapports entre le corps et l'image.
Palavras-chave: dança contemporânea; espetáculo; corpo; política; subjetividade.

Key words: contemporary dance/; spectacle; body; politics; subjectivity.

Mots-clés: danse contemporaine/; spectacle; corps; politique; subjectivité.
Recebido em: $25 / 02 / 2010$

Aprovado em: $15 / 03 / 2010$ 